\title{
Fluid reservoirs in the crust and mechanical coupling between the upper and lower crust
}

\author{
Bruce E Hobbs ${ }^{1}$, Alison Ord ${ }^{1}$, Klaus Regenauer-Lieb ${ }^{1,3}$, and Barry Drummond ${ }^{2}$ \\ ${ }^{1}$ CSIRO Exploration and Mining, Perth, Australia \\ ${ }^{2}$ Geoscience Australia, Canberra, Australia \\ ${ }^{3}$ University of Mainz, Germany
}

(Received June 15, 2004; Revised November 29, 2004; Accepted December 15, 2004)

\begin{abstract}
An important observation associated with seismic activity on the Nagamachi-Rifu Fault is the existence of tabular, fluid rich zones at mid-crustal levels. These zones resemble the "bright spots" seen in many seismic images of the crust worldwide. The aim of this paper is to develop the mechanical foundations for the formation of such zones. To do so requires an understanding of the distribution of pore fluid pressure in a deforming crust. In a hydrostatically stressed porous material, the pore fluid pressure should equal the mean stress in order to keep the pores from collapsing. Past discussions of this subject imply very high pore fluid pressures, two to three times lithostatic. Considerations of plastic yielding together with continuity arguments, particularly at the plastic/viscous transition, suggest that pressures closer to lithostatic are more the norm. Particularly just below the plastic/viscous transition in compressive regimes, this leads to collapse of porosity with an associated collapse in permeability resulting in an over-pressured region comprising that part of the lower crust that is characterised by high mean stress. The base of the plastic region is at a strong discontinuity in stress difference where localised deformation occurs. Tabular, dilatant fluid filled regions develop at and above this zone in close association with dilatant tensional zones in the hanging-walls of faults and diffuse shear zone development in the upper to mid crust. Some of these dilatant zones ultimately develop into listric transitions between steeply dipping, upper crustal faults and shear zones associated with the plastic/viscous transition. These zones are also the sites of strong mineral alteration that may, particularly in ancient examples, also contribute to the delineation of "bright spots" in seismic images. For high geothermal gradients another class of fluid filled layers, in the form of "stagnant fluid zones", develops below the region of high mean stress in the viscous lower crust. Mineral alteration associated with this second class of fluid rich layers is predicted to be asymmetric in distribution as opposed to the first class that would be homogeneous in the mode of alteration.
\end{abstract}

Key words: Fluid reservoirs, bright spots, plastic viscous transition.

\section{Motivation}

Iio and Kobayashi (2002), in introducing the First Sendai Conference, proposed that seismogenic faults in the upper crust may be associated with localised extensions into the lower, viscous crust and that aseismic accumulation of strain within these aseismic zones ultimately nucleates seismic failure on the upper crustal fault. Further more, they proposed that precursor, aseismic slip accelerates prior to the seismic event and that such accelerated motion may be expressed as accelerated tilt and/or distortion at the surface, thereby providing an observable precursor deformation in advance of a major seismic event.

The proposal is that there is an example of such a downward continuation of a seismogenic fault in the Sendai region of NE Japan where the Nagamachi-Rifu Fault can be imaged by seismic methods down to the base of the seismogenic zone. This fault was the site of a magnitude 5 earthquake in 1998 at a depth of $12 \mathrm{~km}$. In addition, seismic studies reveal the existence of a thin, shallow dipping

Copy right(c) The Society of Geomagnetism and Earth, Planetary and Space Sciences (SGEPSS); The Seismological Society of Japan; The Volcanological Society of Japan; The Geodetic Society of Japan; The Japanese Society for Planetary Sciences; TERRAPUB
S-wave reflector, below the base of the seismogenic zone, which is interpreted as a fluid filled shear zone (see Umino et al., 2002; Drummond et al., 2004, this volume). It is proposed that localised, aseismic shear flow within this shallow dipping zone preceded and nucleated the main seismic event on the Nagamachi-Rifu Fault higher in the crust.

These observations prompt the following important questions regarding earthquake nucleation:

- What are the processes that lead to the accumulation of fluid rich regions in the mid crust?

- What is the geometry of such regions?

- Are these regions shear zones that could act as sites for aseismic slip?

In order to address these questions, this paper is structured as follows: Since we are concerned with the origin and significance of fluid filled regions in the crust it is fundamental that we first establish the fluid pressure distribution in the crust; we consider this in Section 2. If one equates the pore fluid pressure with the mean stress and follows the discussions of Petrini and Podladchikov (2000) and Stuwe and Sandiford (1994) then one concludes that the pore fluid 
pressures can be considerably larger than lithostatic. We attempt to resolve discrepancies between these results and the "classical" assumption that the fluid pressure below some relatively shallow seal is approximately lithostatic in Section 2 . The transition between dominantly plastic and dominantly viscous behaviour in the crust is commonly portrayed as a detachment zone as well as a region where fluids are "ponded" (see for example, Cox et al., 1990). We consider these issues in Section 3, and in Section 4 we present some numerical simulations designed to clarify the discussion. Finally in Section 5 we present some conclusions with particular relevance to the Sendai example and consider the implications of using elastic-plastic-viscous constitutive laws to represent the mechanical behaviour of the crust.

\section{Fluid Pressure Distribution in the Crust 2.1 Introduction}

For simplicity we consider a two dimensional situation with Cartesian coordinate axes $x_{i}(i=1,2)$ and $x_{2}$ vertical, in which the total stresses are $\sigma_{i j}$, with $\sigma_{1} \geq \sigma_{2}$ and compressive stresses positive. We define the deviatoric stresses to be $\sigma_{i j}^{\prime}$ given by:

$$
\sigma_{i j}^{\prime}=\sigma_{i j}-\delta_{i j} \sigma^{o}
$$

where $\sigma^{o}$ is the mean normal stress in the rock mass, i.e., $\sigma^{o}=\sigma_{k k} / 2 . \delta_{i j}$ is the Kronecker delta. We also define the effective stresses by:

$$
\begin{gathered}
\sigma_{i j}^{\text {eff }}=\sigma_{i j}-\delta_{i j} P_{f} \\
\sigma_{i j}^{/ \text {eff }}=\sigma_{i j}^{\prime}-\delta_{i j} P_{f}
\end{gathered}
$$

where $P_{f}$ is the fluid pressure in the rock pore space. The concept of a deviatoric stress was introduced historically because the constitutive behaviour of viscous (pressure insensitive/temperature sensitive) materials is not (to first order) influenced by normal stresses but by only the shear stresses (see Nadai, 1950). On the other hand, the constitutive behaviour of plastic (pressure sensitive/temperature insensitive) materials is strongly influenced by normal stresses. Thus, the concept of effective stress was introduced (see Paterson, 1978 for a discussion) specifically for the plastic deformation of materials where the strain is influenced by the pore fluid pressure that tends to force the grains apart. The notions surrounding the concepts of deviatoric stress and effective stress are commonly used interchangeably in a loose manner in the geoscience literature but the distinctions between them become fundamental in the following discussion. Note that from (1) and (2),

$$
\begin{gathered}
\left(\sigma_{1}-\sigma_{2}\right)=\left(\sigma_{1}^{\prime}-\sigma_{2}^{\prime}\right)=\left(\sigma_{1}^{\text {eff }}-\sigma_{2}^{\text {eff }}\right) \\
\left(\sigma_{1}+\sigma_{2}\right)=\left(\sigma_{1}^{\prime}+\sigma_{2}^{\prime}\right)+2 \sigma^{o}=\left(\sigma_{1}^{\text {eff }}+\sigma_{2}^{\text {eff }}\right)+2 P_{f}
\end{gathered}
$$

What defines the values and orientations of principal stresses in a deforming rock mass? In general the constitutive relations plus the boundary conditions define the values and orientations of principal stresses. In addition, in materials that exhibit yield behaviour, an extra requirement is the existence of a flow rule. However some general statements can be made without becoming specific about constitutive relations and boundary conditions. The condition for dynamic equilibrium is given by the generalisation of Newton's first law of motion:

$$
\rho_{r} \frac{\partial u_{i}}{\partial t}=\frac{\partial \sigma_{i j}}{\partial x_{j}}+\rho_{r} g_{i}
$$

where $\rho_{r}$ is the rock density, $u_{i}$ are the components of the particle velocity and $g_{i}$ are the components of the acceleration due to gravity. If we neglect particle accelerations and shear stresses parallel to $x_{1}$ and $x_{2}$, and gradients in stress parallel to $x_{1}$, then (4) reduces to:

$$
\frac{\partial \sigma_{22}}{\partial x_{2}}=-\rho_{r} g_{2}
$$

so that for these conditions the vertical normal stress (which under these conditions is equal to $\sigma_{2}$ ) is given by $\rho_{r} g h$ where $h$ is the vertical distance below the surface of the Earth and $g=g_{2}$ is the vertical component of the acceleration due to gravity. If particle accelerations are significant or shear stresses parallel to $x_{1}$ and $x_{2}$ are important, as is the case with regional buckling or the development of horizontal detachment zones then (5) is not necessarily approximately true. Some examples are given by Petrini and Podladchikov (2000).

For a power law viscous material, the value of $\sigma_{1}$ is then fixed by the constitutive relation and (3a):

$$
\sigma_{1}-\sigma_{2}=\sigma_{1}^{\prime}-\sigma_{2}^{\prime}=A^{1 / N} D^{1 / N} \exp \{Q / N R T\}
$$

where $A$ is a material constant, $D$ is the deformation rate, $Q$ is an activation energy, $R$ is the gas constant, $T$ is the absolute temperature and $N$ is an exponent normally in the range 1-5 (see Nicolas and Poirier, 1976). It is important to note that the constitutive relation for power-law viscous materials is written in terms of the second invariant of the deviatoric stresses, but can be reduced to (6) (see Jaeger, 1962).

For a plastic material, typically represented by a MohrCoulomb or a Drucker-Prager material, or some variant between these two extremes (see Borja and Aydin, 2004, 2686-2693), the stress state is governed by a flow rule which specifies the direction and magnitude of the incremental plastic strain as a vector normal to a plastic potential surface which, in turn, is defined in terms of $q$, a scalar function of the stresses and of the dilatancy of the material. For a Mohr-Coulomb material (see Vermeer and de Borst, 1984):

$$
q=\sigma_{1}^{\mathrm{eff}}-N_{\varphi} \sigma_{2}^{\mathrm{eff}}-2 c \sqrt{N_{\varphi}}
$$

Here, $N_{\varphi}=(1+\sin \varphi) /(1-\sin \varphi), c$ is the cohesion and $\varphi$ is the dilation angle. The stress rate can then be expressed in terms of the deformation rate and the total (elastic plus plastic) strain rate (see Vermeer and de Borst, 1984, p. 24). In general the stress rate cannot be analytically integrated to obtain the stresses for a given strain history and numerical procedures are required. Thus the values and orientations of the principal stresses in a Mohr-Coulomb material are 

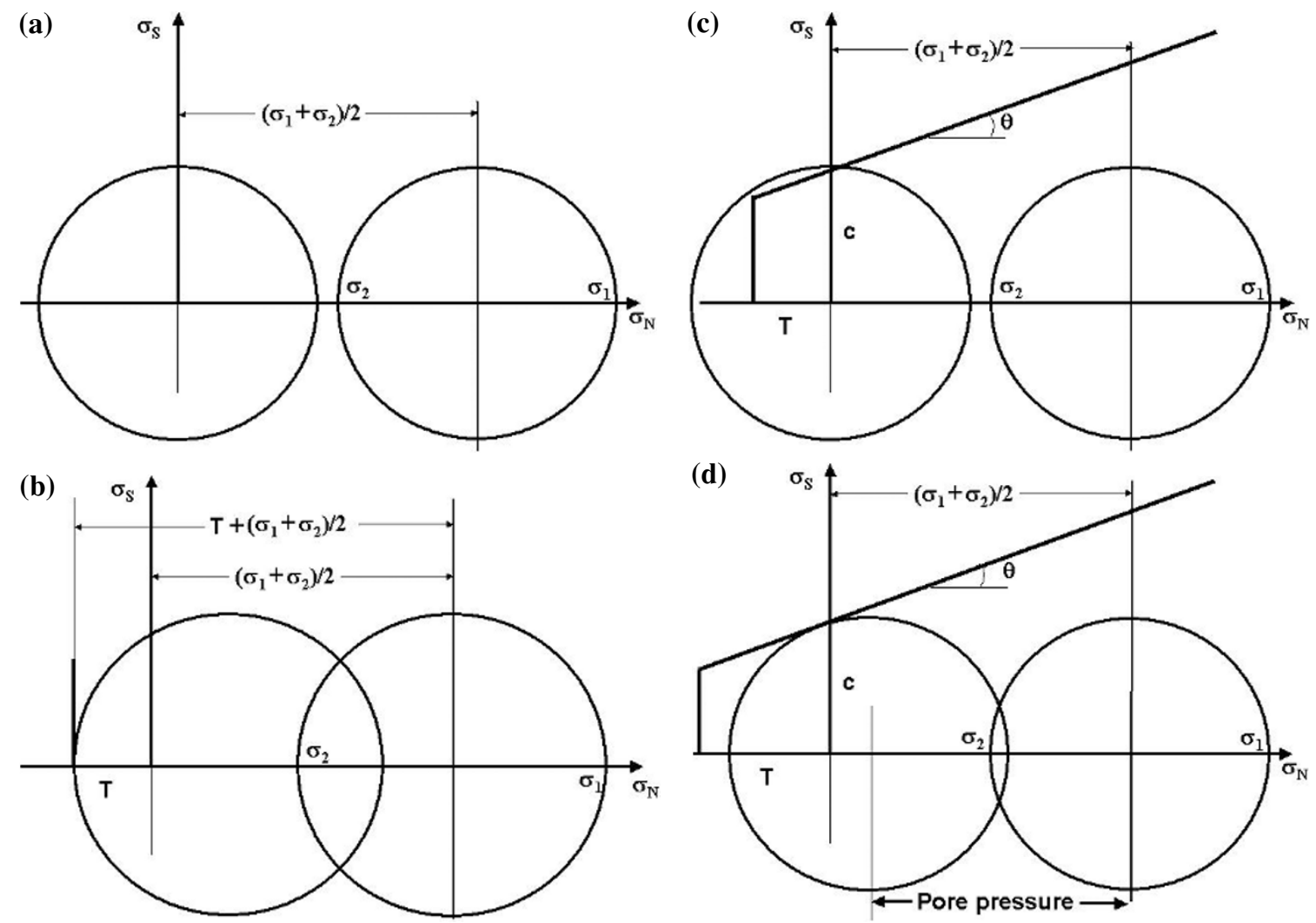

Fig. 1. Mohr diagrams showing the influence of various assumptions concerning the fluid pressure on the effective stress state. (a) Transformation, due to a fluid pressure equal to the mean stress, of a stress state defined by $\sigma_{1}$ and $\sigma_{2}$ in a viscous solid with no tensile yield. (b) Transformation, due to a fluid pressure less than the mean stress, of a stress state defined by $\sigma_{1}$ and $\sigma_{2}$ in a viscous solid with a tensile yield stress, $T$. (c) Transformation, due to a fluid pressure equal to the mean stress, of a stress state defined by $\sigma_{1}$ and $\sigma_{2}$ in a Mohr-Coulomb solid with a tensile yield stress, $T$, and failure envelope defined by the cohesion, $c$, and the friction angle, $\theta$. The effective stress state now exceeds both the Mohr-Coulomb failure envelope and the tensile failure criterion and hence cannot be sustained. (d) Transformation, due to a fluid pressure that just enables yield to occur, of a stress state defined by $\sigma_{1}$ and $\sigma_{2}$ in a Mohr-Coulomb solid with a tensile yield stress, $T$, and failure envelope defined by the cohesion, $c$, and the friction angle, $\theta$.

not defined solely by the boundary conditions and constitutive relation, as is the case in an elastic or a power-law viscous material, but also by the history of incremental strains, which in turn is a function of the history of dilatancy and of the history of fluid pressure.

\subsection{Pore pressure distribution in deforming materials}

It is widely observed that the uppermost crust is divided into more or less horizontal compartments in which the pore pressure gradient alternates between approximately hydrostatic and approximately lithostatic (see Hunt, 1990). In the absence of a non-hydrostatic stress field, over a specific column of rock, the mean pore pressure and the mean pore pressure gradient must be lithostatic. This follows from the fact that in a porous rock under a hydrostatic stress state the fluid pressure in the rock must be less than or sufficient to keep the pore space open, so that if the confining pressure is close to the strength of the rock, the pore pressure at a particular point must be similar in magnitude to the mean pressure given by $\rho_{r} g h$. This is the value of pore pressure classically adopted by metamorphic petrologists. The observed distribution of compartments seems to be the result of selforganisation resulting from two competing processes:

1. The tendency to move towards a global equilibrium state where the pore pressure gradient is everywhere hydrostatic even though the mean pore fluid pressure is lithostatic. The time scale, $\tau$, for this to happen is given by the diffusion equation,

$$
\tau=L^{2} / \kappa
$$

where $L$ is a length scale for the system and $\kappa$ is the hydraulic diffusivity that in turn is given by (see Phillips, 1991)

$$
\kappa=K c^{2} / \mu \phi
$$

where $c$ is the isothermal speed of sound in the rock (ca. $\left.1.4 \times 10^{3} \mathrm{~ms}^{-1}\right), \mu$ is the kinematic viscosity of the fluid (for water at $0^{\circ} \mathrm{C}$ ca. $10^{-6} \mathrm{~m}^{2} \mathrm{~s}^{-1}$ ), and $\phi$ is the porosity. This means that for a rock with porosity 0.1 , the magnitude of $\kappa$ is ca. $1.96 \times 10^{13} \mathrm{~K}$. Hence, layers $5 \mathrm{~km}$ thick, of different permeabilities, will evolve towards this global hydrostatic state at different rates depending upon their permeabilities. A layer with permeability of $10^{-17} \mathrm{~m}^{2}$ will take ca. 3,950 years to reach an equilibrium hydrostatic gradient condition whereas the same thickness layer with permeability $10^{-18} \mathrm{~m}^{2}$ will take ca. 39,500 years. These time scales are short geologically so that in the absence of devolatilisation or supply of fluids from the mantle, a lithospheric pore pressure gradient will rapidly relax to a hydrostatic gradient.

2. The mechanical necessity that only columns of finite height of fluid with hydrostatic pore pressure gradients can be supported. This height is controlled by the generation of tensile effective stresses at the top of the column that 
hydrofracture the top of the column and the generation of compressive deviatoric stresses at the base of the column that tend to close the pore space by viscous flow. The height of these compartments varies according to whether the stress state is hydrostatic, compressive, extensional or transpressive.

The development of fluid pressure compartments by these processes has been elegantly discussed by Connolly and Podladchikov (2000). The above discussion is true for a rock mass under hydrostatic stress conditions. If the rock mass is deforming, other considerations need to be made and these are considered below.

2.2.1 Pore pressure in deforming power-law viscous material We first explore the proposal that for a porous power-law viscous material under non-hydrostatic stress the pore pressure needed to keep the pores open is equal to the mean total stress, $\left(\sigma_{1}+\sigma_{2}\right) / 2$ (Fig. 1(a)). This can be substantially greater than the lithostatic pressure since the mean deviatoric stress in such a material (see Stuwe and Sandiford, 1994) is:

$$
\left(\sigma_{1}^{\prime}+\sigma_{2}^{\prime}\right) / 2=\sigma_{2}^{\prime}+0.5 A^{1 / N} D^{-1 / N} \exp \{Q / N R T\}
$$

From (6) and (3) the mean total stress in a power law viscous material is given by:

$$
\left(\sigma_{1}+\sigma_{2}\right) / 2=\sigma_{2}+0.5 A^{1 / N} D^{-1 / N} \exp \{Q / N R T\},
$$

which approaches $\sigma_{2}$ as $T$ increases and/or $D$ decreases.

If $\sigma_{2}$ is solely due to the overburden pressure (as indicated by Eq. (5)) then the mean stress approaches lithostatic for high $\mathrm{T}$ and/or low D but otherwise is substantially larger (see Stuwe and Sandiford, 1994 for a discussion).

The above discussion regarding the magnitude of the pore fluid pressure in a deforming porous power law material is true so long as the material can support relatively large tensile effective deviatoric stresses. If the viscous material exhibits a tensile failure mode then the situation is better represented by Fig. 1(b). It should be noted that experimental work in order to establish constitutive relations for power law viscous materials containing fluids is singularly lacking. Some of the best approaches are those of Tvergaard (1987), Needleman (1994) and Bercovici and Ricard (2002) discussed by Regenauer-Lieb (1999) and Regeneauer-Lieb and Yuen (2003). These constitutive relations show yield behaviour, a feature that is lacking in the classical constitutive relations for geological viscous materials and such yield behaviour would further restrict the possible states of fluid pressure as illustrated for plastic materials below.

2.2.2 Pore pressure in a deforming plastic, MohrCoulomb material In the upper part of the crust, the deformation style is dominated by plastic (that is, pressure dependent, temperature independent) constitutive behaviour. Various forms of behaviour may be assumed but the common one is characterised by the Mohr-Coulomb constitutive law where the constitutive behaviour is characterised by a yield surface defined (see Vermeer and de Borst, 1984) by:

$$
f=\sigma_{1}^{\text {eff }}-N_{\theta} \sigma_{2}^{\text {eff }}-2 c \sqrt{N_{\theta}}
$$

Here, $f$ is the yield function, $N_{\theta}=(1+\sin \theta) /(1-\sin \theta)$, $c$ is the cohesion and $\theta$ is the friction angle. Note the resemblance to the plastic potential function, $q$, defined in (7). If $f=q$ the constitutive relation is associative; otherwise it is non-associative. For $f=0$ the material is at plastic yield in shear and for $\partial f / \partial t=0$, remains at yield, where $t$ is time; for $f<0$ the material is undergoing elastic deformation; the material cannot support stress states for which $f>0$. It follows from (12) and (3) that, at yield:

$$
\left(\sigma_{1}+\sigma_{2}\right) / 2=\sigma_{2}\left(N_{\theta}+1\right) / 2-P_{f}\left(N_{\theta}-1\right) / 2+c \sqrt{N_{\theta}}
$$

For $\theta=30^{\circ}, N_{\theta}=3$ and so, $\left(\sigma_{1}+\sigma_{2}\right) / 2=\rho_{r} g h+c \sqrt{3}$ for $\sigma_{2}=\rho_{r} g h=P_{f}$. Notice also that the shear stress is given by:

$$
\left(\sigma_{1}-\sigma_{2}\right) / 2=\sigma_{2}\left(N_{\theta}-1\right) / 2-P_{f}\left(N_{\theta}-1\right) / 2+c \sqrt{N_{\theta}}
$$

For $\theta=30^{\circ}$ and $\sigma_{2}=\rho_{r} g h=P_{f},\left(\sigma_{1}-\sigma_{2}\right)=2 c \sqrt{3}$. Here $P_{f}$ is the pore fluid pressure and in this instance corresponds to that pore fluid pressure required to induce yield. Also, if $P_{f}=0$ in Eq. (13), then one recovers the result of Petrini and Podladchikov (2000) that the mean stress in a dry, cohesionless Mohr-Coulomb material with $\theta=30^{\circ}$ is $2 \rho_{r} \mathrm{gh}$. However, the outcome of assuming the pore fluid pressure is equal to the mean stress is illustrated in Fig. 1(c) where it is clear that the effective stress state now exceeds the yield in shear and commonly also in tension.

Although Eqs. (13) and (14) give the mean stress and the shear stress at yield for a plastic material we still need the pore pressure needed to take the total stress to yield (see Fig. 1(d)). This is given by:

$$
P_{f}=\left(\sigma_{1}+\sigma_{2}\right) / 2-\left(\sigma_{1}-\sigma_{2}\right) / 2 \sin \theta+c / \tan \theta .
$$

This is the pore pressure at failure that just keeps the pore space open without exceeding the yield stress. For $\theta=30^{\circ}$ the largest $\sigma_{1}$ can be is $\left(3 \sigma_{2}+2 c \sqrt{3}\right)$ which corresponds to the situation where the stress circle just touches the failure envelope with no fluid present. Otherwise, if one assumes that $\sigma_{2}=\rho_{r} g h$, then $P_{f}$ is always less than $\left(3 \rho_{r} g h+\right.$ $2 c \sqrt{3}) / 2$ and, in particular, the fluid pressure is hydrostatic for $\sigma_{1}=2.26 \rho_{r} g h+2 c \sqrt{3}$ assuming a crustal density of $2700 \mathrm{~kg} \mathrm{~m}^{-3}$. Thus it is quite possible in a deforming MohrCoulomb material to have a hydrostatic pore fluid pressure that satisfies the mechanical constraints of keeping the pore volume open.

2.2.3 Implications for fluid flow regimes in the crust The governing equations for pore fluid flow are (see Bear, 1972; Scheidegger, 1974):

$$
\begin{gathered}
\frac{\partial v_{1}}{\partial x_{1}}+\frac{\partial v_{2}}{\partial x_{2}}=0 \\
v_{1}=\frac{K}{\mu}\left(-\frac{\partial P_{f}}{\partial x_{1}}\right) \\
v_{2}=\frac{K}{\mu}\left(-\frac{\partial P_{f}}{\partial x_{2}}+\rho_{f} g\right)
\end{gathered}
$$

where $v_{i}$ are the components of Darcy fluid flow velocity, $K$ is the permeability, $\mu$ is the dynamic fluid viscosity, $\rho_{f}$ is the fluid density. Equation (16) is the continuity equation that describes the mass conservation of pore-fluid at each 
point in the crust for an incompressible fluid with no internal fluid sources; Eqs. (17) and (18) are the Darcy equations for flow along horizontal and vertical pressure gradients in the crust. In the simple case we want to consider here we assume that there is no horizontal pore pressure gradient and so $v_{1}=0$ and (16) reduces to $\partial v_{2} / \partial x_{2}=0$. Connolly and Podladchikov (2004) have discussed the significance of assuming the fluid pressure to be equal to the mean stress in the viscous regime and have shown, on the basis of such an assumption, that just beneath the plastic/viscous transition there exists a regime where the gradient of hydraulic head is negative so that fluid flow is downwards. Below this is a regime where the gradient in hydraulic head is zero; this corresponds to a regime of stagnant fluid flow. Connolly and Podladchikov then proceed to discuss the implications of the existence of these regimes for the interpretation of layering identified by seismic imaging in the lower crust. We explore these concepts further in Sections 3, 4 and 5.

\section{Coupling between the Upper and Lower Crust}

Application of Eqs. (16) and (18) indicates that at the boundary between plastic and viscous materials, the vertical component of fluid flow and the gradient of pore pressure must be continuous. If one adopts (15) and (11) as the equations for the pore fluid pressure in the plastic and viscous regimes respectively, then these conditions of continuity are not fulfilled at the boundary in the general case, since the pore pressure in the viscous material at the boundary exceeds that in the plastic material by approximately $\left[0.5 A^{1 / N} D^{-1 / N} \exp \{Q / N R T\}\right]$. The maximum pore pressure at the boundary is fixed by the plastic material and since the matching pore pressure in the viscous material needs to be significantly less than that given by (11), the pore space in the viscous material must collapse with a resultant decrease in permeability. This collapse in permeability presumably results in very low permeabilities however increases in permeability induced by deformation can result in the transient development of higher permeability. This has been incorporated into the numerical models presented in Section 4 in the form of hydrofracturing; this means that for plastic materials, if $f=0$, where $f$ is the yield condition defined by (12), or the tensile yield strength is reached for plastic or viscous materials then the permeability is increased by a factor of ten. Thus the outcome of imposing conditions of continuity of fluid flow across the plastic-viscous boundary is the development of a low permeability boundary just below the interface with overpressured fluid below the layer. The thickness of this layer is governed by Eqs. (15) and (11) and hence is a function of the geothermal gradient and the constitutive parameters relevant to a particular lithology.

\section{A Numerical Example \\ 4.1 Properties of the model}

In order to be specific about the principles discussed above we present a numerical example of a section through the crust, $100 \mathrm{~km}$ wide and $30 \mathrm{~km}$ deep. The top $15 \mathrm{~km}$ is comprised of a plastic, elastic-Mohr-Coulomb material whilst the lower $15 \mathrm{~km}$ is comprised of an elastic-power law viscous material. The crust is lithologically homoge-

\section{INITIAL CONDITIONS FOR THE MODEL}

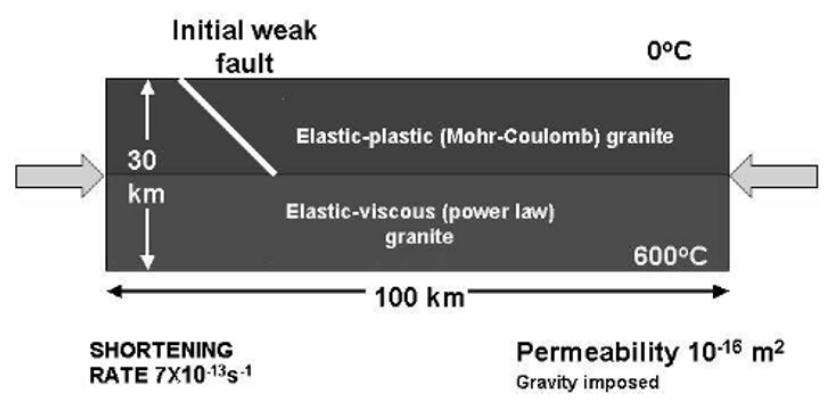

Fig. 2. Initial geometry and boundary conditions for the numerical models. Some models were run with the lower temperature fixed at $1200^{\circ} \mathrm{C}$.

neous with constitutive properties similar to those of granite (see Table 1). A weaker, plastic fault dipping at $45^{\circ}$ is included in the plastic part of the crust in order to simulate the Nagamachi-Rifu Fault in the Sendai situation (see Fig. 2). The temperature at the top of the crust is fixed at $0^{\circ} \mathrm{C}$ whilst that at the base is fixed at $600^{\circ} \mathrm{C}$, corresponding to the Sendai situation. We also consider the result of increasing the thermal gradient so that the base of the crust is $1200^{\circ} \mathrm{C}$. The crust is fully saturated with water. No advection of heat in the fluid as it moves is included. The fluid pressure in the plastic part of the model is given by Eq. (15). The permeability of the crust is set initially everywhere at $10^{-15} \mathrm{~m}^{2}$. The results flowing from these models are insensitive to the absolute values of permeability assumed so the values selected here are somewhat arbitrary. Although somewhat higher values (say $10^{-18} \mathrm{~m}^{2}$ may be measured in intact core, it is widely observed (see for instance, Scheidegger, 1974) that permeabilities measured at a regional scale are generally several orders of magnitude larger than laboratory determined values due to the existence of other imperfections such as joints at the larger scale. Hence values of $10^{-15} \mathrm{~m}^{2}$ to $10^{-16} \mathrm{~m}^{2}$ are reasonable. In the viscous part of the crust, if the mean stress given by Eq. (11) is greater than $\left(\sigma_{2}+T\right)$, where $\mathrm{T}$ is the tensile strength of the viscous material, the pore pressure is set at $\left(\sigma_{2}+T\right)$ and the permeability collapsed to $10^{-16} \mathrm{~m}^{2}$; otherwise the pore pressure is set to $\sigma_{2}$. The model is shortened horizontally at $0.7 \times 10^{-13} \mathrm{~s}^{-1}$ with roller boundary conditions at the base of the model. In order to simulate natural observations, a pressure seal consisting of a layer with permeability $10^{-16} \mathrm{~m}^{2}$ is placed at a depth of $3 \mathrm{~km}$ with a hydrostatic fluid pressure gradient above the seal.

An explicit, commercially available, finite difference program is used (Fast Lagrangian Analysis of Continua, FLAC) to explore the non-linear behaviour within this model. In the finite difference method (see for example Desai and Christian 1977), every derivative in the set of governing equations is replaced directly by an algebraic expression written in terms of the field variables (e.g., stress or displacement) at discrete points in space; these variables are undefined within elements although physical and chemical parameters such as elastic moduli, permeability and thermal conductivity are defined within elements. The dynamic equations of motion are included in the formulation 
Table 1. Physical properties used in numerical models

\begin{tabular}{|c|c|}
\hline Property: units & Value \\
\hline \multicolumn{2}{|l|}{$\begin{array}{l}\text { Elastic mohr coulomb and power law } \\
\text { viscous materials: }\end{array}$} \\
\hline Shear Modulus (plastic layer): $\mathrm{Pa}$ & $2.8 \times 10^{9}$ \\
\hline Shear Modulus (viscous layer): $\mathrm{Pa}$ & $5.47 \times 10^{10}$ \\
\hline Bulk Modulus (plastic layer): $\mathrm{Pa}$ & $4.67 \times 10^{9}$ \\
\hline Bulk Modulus (viscous layer): $\mathrm{Pa}$ & $10.61 \times 10^{10}$ \\
\hline Bulk Modulus (water): $\mathrm{Pa}$ & $2 \times 10^{8}$ \\
\hline Friction Angle (bulk material): degrees & 30 \\
\hline Friction Angle (fault): degrees & 20 \\
\hline Dilation Angle (bulk material): degrees & 1 \\
\hline Dilation Angle (fault): degrees & 10 \\
\hline Cohesion (bulk material): $\mathrm{Pa}$ & $2 \times 10^{7}$ \\
\hline Cohesion (fault): $\mathrm{Pa}$ & $1 \times 10^{7}$ \\
\hline Tensile cut off: $\mathrm{Pa}$ & $2 \times 10^{6}$ \\
\hline Density of Rock: $\mathrm{kg} \mathrm{m}^{-3}$ & 2700 \\
\hline Density of Water: $\mathrm{kg} \mathrm{m}^{-3}$ & 1000 \\
\hline$N$ & 1.8 \\
\hline$Q: \mathrm{J} \mathrm{mol}^{-1}$ & $151 \times 10^{3}$ \\
\hline$A: \mathrm{Pa}^{-N} \mathrm{~s}^{-1}$ & $4.17 \times 10^{-20}$ \\
\hline Thermal Conductivity: $\mathrm{W} \mathrm{m}^{-1} \mathrm{~K}^{-1}$ & 2.5 \\
\hline Specific Heat: $\mathrm{J} \mathrm{kg}^{-1} \mathrm{~K}^{-1}$ & $1.255 \times 10^{3}$ \\
\hline \multicolumn{2}{|l|}{ Burger material (Fig. 7): } \\
\hline Kelvin bulk modulus: $\mathrm{Pa}$ & $11.66 \times 10^{10}$ \\
\hline Kelvin shear modulus: $\mathrm{Pa}$ & $7.0 \times 10^{10}$ \\
\hline \multicolumn{2}{|l|}{ Kelvin viscosity: Pa s; given by $\eta=\eta_{0} \exp \left(Q_{B} / R T\right)$} \\
\hline$\eta_{0}: \mathrm{Pa} \mathrm{s}$ & $2.844 \times 10^{19}$ \\
\hline$Q_{B}: \mathrm{J} \mathrm{mol}^{-1}$ & 13307 \\
\hline Maxwell bulk modulus: $\mathrm{Pa}$ & $11.66 \times 10^{10}$ \\
\hline Maxwell shear modulus: $\mathrm{Pa}$ & $7.0 \times 10^{10}$ \\
\hline \multicolumn{2}{|l|}{ Maxwell viscosity $=$ Kelvin viscosity } \\
\hline Mohr-Coulomb cohesion (bulk material): $\mathrm{Pa}$ & $1.0 \times 10^{7}$ \\
\hline Mohr-Coulomb cohesion (fault): $\mathrm{Pa}$ & $1.0 \times 10^{7}$ \\
\hline Mohr-Coulomb friction angle (bulk material): degrees & 30 \\
\hline Mohr-Coulomb friction angle (fault): degrees & 20 \\
\hline Mohr-Coulomb dilation angle (bulk material): degrees & 10 \\
\hline Mohr-Coulomb dilation angle (fault): degrees & 0 \\
\hline Tensile cut off: $\mathrm{Pa}$ & $5.0 \times 10^{6}$ \\
\hline
\end{tabular}

with the aim of ensuring that the numerical scheme is stable when the physical system being modelled is unstable. Inertial terms are included and kinetic energy is generated and dissipated.

The general calculation procedure (ITASCA, 2002) for the coupled deformation-fluid flow-thermal conduction problem explored here involves three distinct modes; these three modes correspond respectively to the individual processes of deformation, fluid flow and thermal conduction and they are performed sequentially during the calculation. The first, or deformation mode, first invokes the equations of motion to derive new velocities and displacements from stresses and forces. Second, strain rates are derived from velocities, and new stresses from strain rates using defined constitutive relations and flow rules. This mode uses inputs such as temperature and pore fluid pressure from other modes to calculate dependent parameters such as strainrate or effective stress. The second, or fluid flow mode, invokes Darcy's Law to derive new Darcy flow velocities from pore pressure updates supplied by the deformation mode; these pore pressure changes are induced by dilational changes during deformation. The third, or thermal conduction mode, invokes Fourier's Law to derive the new temperature distribution in the crust given the deformation that has occurred up to that stage. As indicated elsewhere, advection of heat in the moving fluid is not explored in this paper. This new temperature is passed on to the next deformation mode to influence the strain rate and stress. One time step is taken for one full computational cycle. Time steps are chosen for each of the deformation, fluid flow, and thermal transport modes, which are sufficiently small that information cannot physically pass from one element to another in that interval. Disturbances propagate across several elements only after several cycles. The aim is to ensure that the calculation 'wave speed' always keeps ahead of the physical, fluid and thermal wave speeds. These critical time steps are calculated within the program using expressions for the velocity of stress propagation through an elastic solid, and the diffusion equations for transport of fluid pressure in a porous medium and for thermal diffusion. Details are given in the FLAC Users' Manual (ITASCA, 2002). The usual procedure is to perform a number of cycles in the deformation mode with no fluid flow or thermal transport, then switch to the fluid flow mode with no deformation or thermal transport, and then switch to the thermal mode with no deformation or fluid flow. This sequence is then repeated many times. Care must be taken to ensure that throughout this switching, the number of time steps performed within each mode preserves the true physical time for the coupled deformation-fluid flow-thermal transport problem. The program performs a 'Lagrangian' analysis in that coordinates are updated at each time step in large-strain mode; the incremental displacements are added to the coordinates so that the grid moves and deforms with the material it represents.

\subsection{Results of numerical modelling}

Figures 3 and 4 show the distribution of stress, pore pressure and deformation after $2 \%$ total horizontal shortening. Figure 3(a) is the vertical distribution of $\left(\sigma_{1}-\sigma_{2}\right)$ and illustrates the influence of pore pressure particularly on the plastic part of the crust where the concept of effective stress is important. The stress difference in the plastic part of the crust is $2 c \sqrt{3}$ as indicated in Section 2 whereas in the viscous part the stress difference is given by Eq. (6). Some comment is needed on Fig. 3(a) because the distribution of stress difference through the crust is not the classical "Christmas tree" distribution. We address this in Section 5. Figure 3(b) shows the vertical distribution of the mean total stress; this again follows Eqs. (11) and (13); the mean stress is approximately $\left(\rho_{r} g h+c \sqrt{3}\right)$ in the plastic regime but increases rapidly at the plastic/viscous boundary as discussed by Stuwe and Sandiford (1994) and indicated by Eq. (11). Figure 3(c) shows the vertical distribution of pore fluid pressure. Notice that this distribution is close to lithostatic, in the low geothermal gradient example. In the high geothermal gradient example, the pore pressure rises above lithostatic in the region of porosity collapse just below the 
plastic/viscous transition but ultimately recovers to lithostatic towards the base of the crust. The vertical distribution of hydraulic head that follows from Fig. 3(c) in the low geothermal gradient example indicates that there are no regions of downward flow or of stagnant flow whereas in the high geothermal gradient example two stagnant flow layers are developed (see Connolly and Podladchikov, 2004).

Figure 4(a) shows the spatial distribution of $\left(\sigma_{1}-\sigma_{2}\right)$ and highlights the discontinuity of stress difference at the top of the viscous layer. This correlates with a concentration of the maximum shear strain rate in Fig. 4(b) indicating a listric transition from the initial fault dipping at $45^{\circ}$ into a shear zone corresponding to the base of the plastic regime. Figure 4(c) shows the spatial distribution of the mode of plastic failure whilst Figure 4(d) shows the spatial distribution of permeability arising from hydrofracture evolution together with the resulting Darcy flow pattern.

Both the plastic and viscous portions of the crust dilate during deformation and the patterns of dilatancy are shown in Fig. 5 for various amounts of shortening and for the two geothermal gradients of $20^{\circ} \mathrm{C} \mathrm{km}^{-1}$ and $40^{\circ} \mathrm{C} \mathrm{km}^{-1}$. These dilatant regions correspond to regions of higher porosity and hence higher fluid content. It is proposed that these correspond to the "bright-spots" identified in S-wave seismic images. The crust as a whole has deformed in these models by the formation of a plastic wedge as shown in Fig. 6(a). The dilatant regions are commonly tabular in shape with shallow dips and correspond to dilatant zones on the immediate hanging-wall of the fault as shown in Fig. 6(b) or to en echelon dilatant arrays within broad shear zones as shown in Fig. 6(c). This en echelon pattern is particularly well developed in Fig. 5(c). In all cases these dilatant regions have failed in tension and correspond to regions of increased permeability. Fluid flow is instantaneously increased at yield with strong flow upwards across the isotherms as shown in Fig. 4(d). These regions contrast with those proposed by Connolly and Podladchikov (2004) in that they are not "ponding zones" but regions of active upward transport of fluid when yielding occurs.

\section{Summary and Discussion}

At first thought, the proposal that the pore pressure in a deforming rock mass should be equal to the mean rock stress seems quite realistic. However, this situation is not possible in a plastic material characterised by a yield function because in general the material will yield either in shear or tension before this pore pressure is attained. In a MohrCoulomb material with a friction angle of $30^{\circ}$ and with $\sigma_{2}=\rho_{r} g h$ the pore pressure at yield in compression is always less than $\left(3 \rho_{r} g h+2 c \sqrt{3}\right) / 2$. Moreover, in the viscous regime, continuity of normal stress, pore pressure and pore pressure gradient across the plastic/viscous transition means that large pore pressures consistent with the mean stress distribution discussed by Stuwe and Sandiford (1994) cannot be achieved and the pore space within the upper part of the viscous regime must collapse since the pore pressure cannot match the mean rock stress. This situation is reinforced if the viscous material cannot support significant effective tensile stresses when the maximum fluid pressure possible is $\left(\sigma_{2}+T\right)$, or approximately $\left(\rho_{r} g h+T\right)$ where $T$
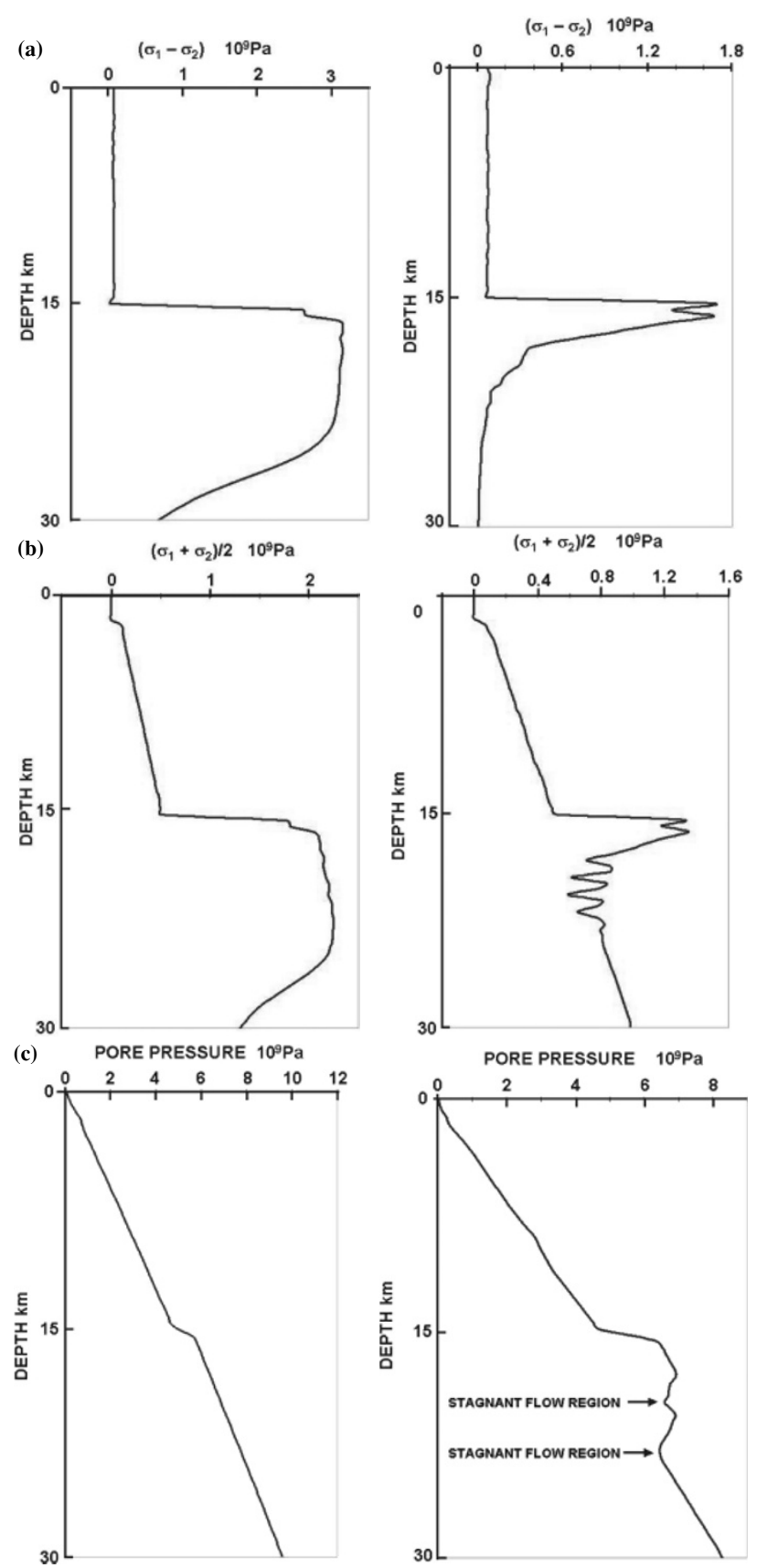

Fig. 3. Plots of stress and pore pressure against depth for low geothermal gradient $\left(20^{\circ} \mathrm{C} \mathrm{km}^{-1}\right)$ on the left and high geothermal gradient $\left(40^{\circ} \mathrm{C}\right.$ $\left.\mathrm{km}^{-1}\right)$ on the right. (a) Plot of $\left(\sigma_{1}-\sigma_{2}\right)$ against depth. (b) Plot of the mean stress, $\left(\sigma_{1}+\sigma_{2}\right) / 2$, against depth. (c) Plot of pore fluid pressure against depth. For the low geothermal gradient, the pore pressure jumps by an amount equal to the viscous tensile strength at the plastic/viscous transition but otherwise the gradient is close to lithostatic except in the top $3 \mathrm{~km}$. For the high geothermal gradient, the pore pressure again jumps by an amount equal to the viscous tensile strength (somewhat exaggerated here to emphasise the effect) at the plastic/viscous transition but otherwise, again, the gradient is close to lithostatic except in the top $3 \mathrm{~km}$. Following the arguments presented by Connolly and Podladchikov (2004) there are now two zones defined in the lower crust where fluid stagnation occurs. Above each of these zones the fluid flow is downwards whilst below each of these zones the fluid flow is upwards.

is the tensile strength of the viscous material.

The outcome is that the fluid pressure distribution through the crust must be close to lithostatic except at the base of the region of porosity collapse below the plas- 
(a)

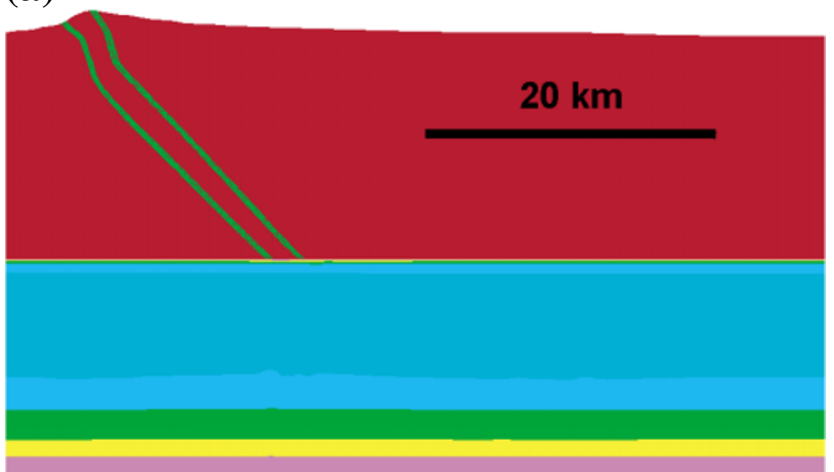

(b)

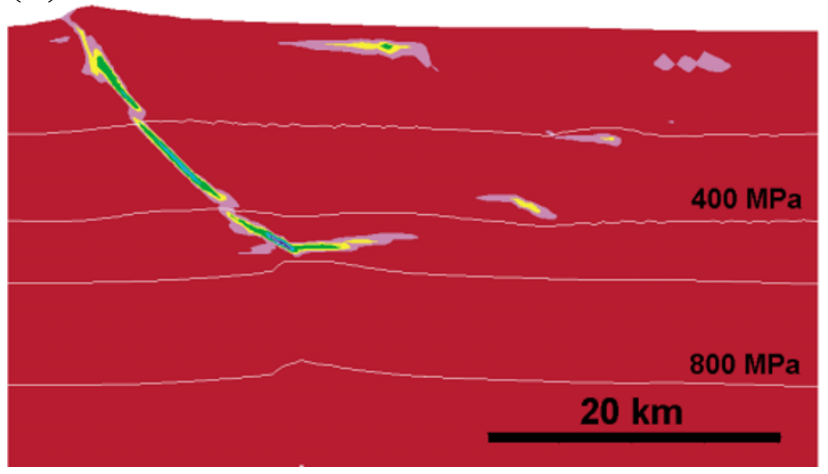

(c)

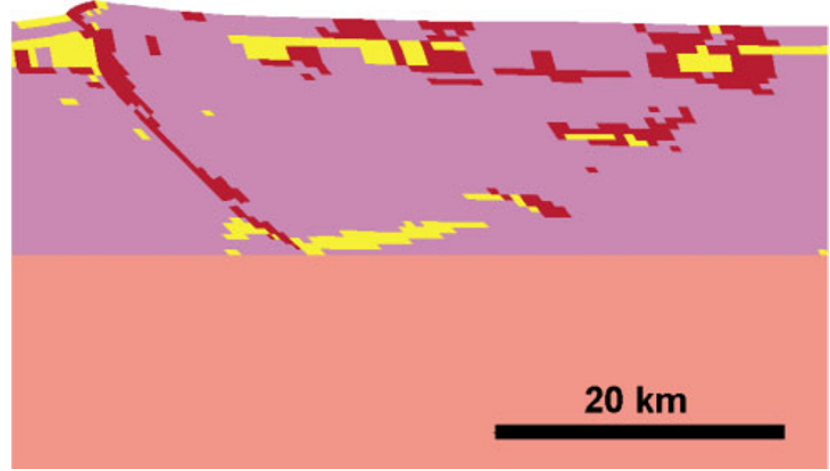

(d)

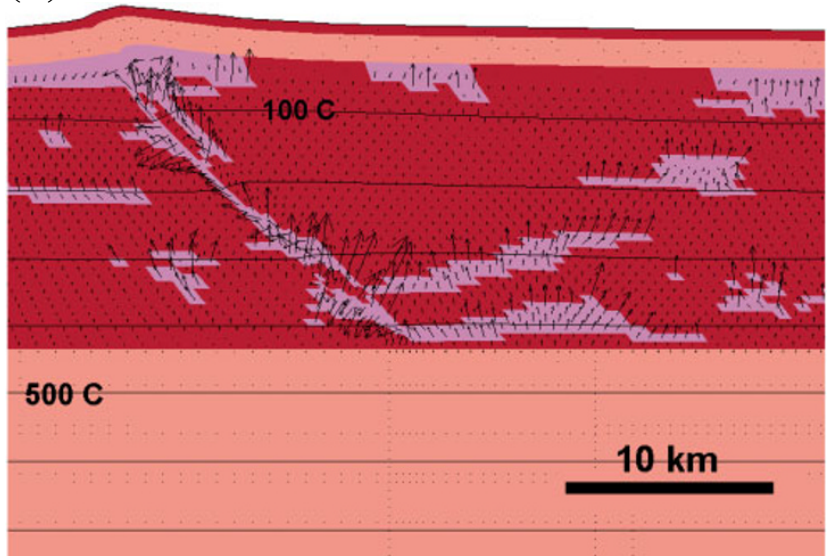

Fig. 4. Zoom into model with low geothermal gradient in vicinity of fault. Total shortening is $2 \%$. (a) Plot of $\left(\sigma_{1}-\sigma_{2}\right)$. Fault outlined in green. Red is minimum and corresponds to $0-500 \mathrm{MPa}$; Darkest blue is maximum and corresponds to $3 \mathrm{GPa}$ and greater. Contour interval: $500 \mathrm{MPa}$. (b) Plot of instantaneous maximum shear strain rate. The highest strain rate is $1.6 \times 10^{-11} \mathrm{~s}^{-1}$ (dark blue); light green is $0.64 \times 10^{-11} \mathrm{~s}-1$; yellow is $3.2 \times 10^{-12} \mathrm{~s}^{-1}$; purple is $1 \times 10^{-12} \mathrm{~s}^{-1}$; strain rate contour interval $3.2 \times 10^{-12} \mathrm{~s}^{-1}$. Contours of pore pressure shown in white; pore pressure contour interval $200 \mathrm{MPa}$. (c) Plot of failure condition; purple: elastic now but has been at yield in the past, yellow: at yield in tension, red: at yield in shear, pink: at yield, viscous. (d) Plot of permeability after permeability has evolved due to hydrofracture. Purple: $10^{-14} \mathrm{~m}^{2}$; dark red: $10^{-15} \mathrm{~m}^{2}$; pink: $10^{-16} \mathrm{~m}^{2}$. Darcy flow vectors in black; maximum flow rate: $5.5 \times 10^{-7} \mathrm{~m} \mathrm{~s}^{-1}$; temperature contours in black, contour interval $100^{\circ} \mathrm{C}$.

tic/viscous transition where regions of down-flow or of fluid stagnation occur if the geothermal gradient is high. The result is a rapid, but continuous, change in the pore pressure at the plastic/viscous transition but the jump is only as large as the tensile strength of the viscous material.

As noted in the text, the distribution of $\left(\sigma_{1}-\sigma_{2}\right)$ through the crust, reported here is not the classical "Christmas tree" distribution and some discussion is needed. In classical discussions of the distribution of stress difference in the crust under compression, Byerlee's Law is taken as defining the distribution of $\left(\sigma_{1}-\sigma_{2}\right)$ for the dry state and the influence of adding a fluid pressure is obtained by the equivalent of the following three steps: (i) loading the crust to very small elastic strain, in the dry state, (ii) injecting fluid at a prescribed pressure into the crust and (iii) compressing the crust until yield occurs (see Sibson, 1974; Ranalli, 1987 , p. 221). Under such conditions, $\sigma_{2}^{\text {eff }}$ is defined by Eqs. (5) and (2) and $\sigma_{1}^{\text {eff }}$ at yield is defined by the yield surface, which, for Byerlee's Law, is that of a cohesionless frictional solid. Under such assumptions, $\left(\sigma_{1}-\sigma_{2}\right)$ can be very large if the pore pressure is small, especially just above the plastic-ductile transition. The approach in this paper is to consider a crust initially saturated with fluid and with a fluid pressure just sufficient to hold the pore space open without causing plastic failure; the crust is then shortened at a given strain rate. $\sigma_{2}$ is then given by Eq. (5) and $\sigma_{1}$ in the plastic regime can be then derived from Eq. (14); as indicated in the text for the constitutive parameters assumed here $\sigma_{1}=\sigma_{2}+2 c \sqrt{3} \approx\left(\rho_{r} g h+6.9 \times 10^{7}\right)$ Pa. The difference between these two approaches lies only in the assumed constitutive relation. In the classical instance this is one of a cohesionless frictional solid; in the present paper the frictional solid has a finite cohesion and hence can also exhibit tensile failure. These two approaches can be compared by rewriting Eq. (14) for a cohesionless solid, so that $c=0$, and substituting $P_{f}=\lambda \rho_{r} g h$ together with $\sigma_{2}=\rho_{r} g h$ (see Ranalli, 1987, p. 221). Then Eq. (14) becomes

$$
\left(\sigma_{1}-\sigma_{2}\right)=\rho_{r} g h(1-\lambda)\left(N_{\theta}-1\right)
$$

from which the classical distributions of stress difference with depth for various imposed pore fluid pressures may be derived. Notice in particular that for $P_{f}=\rho_{r} g h$ in this classical case $\left(\sigma_{1}-\sigma_{2}\right)=0$ since $\lambda=1$, whereas for the Mohr-Coulomb material used here $\left(\sigma_{1}-\sigma_{2}\right)=2 c \sqrt{3}$. Thus for the classical Byerlee type of behaviour the stress at the plastic-viscous transition for lithostatic fluid pressures is zero whist for the Mohr-Coulomb material it is relatively small but finite. Here the stress difference that develops 
(a)

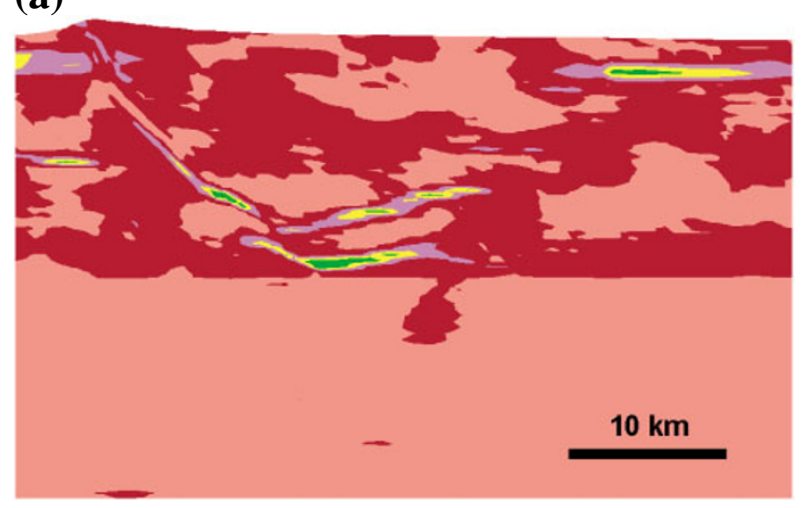

(c)

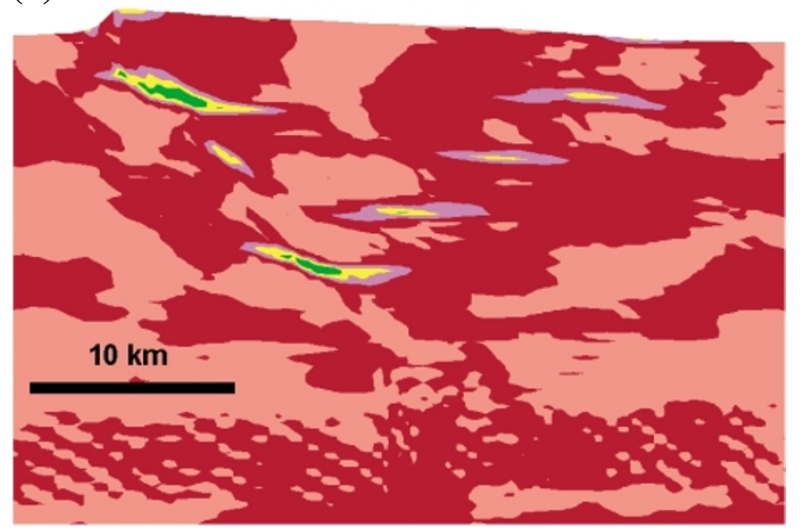

(d)

(b)

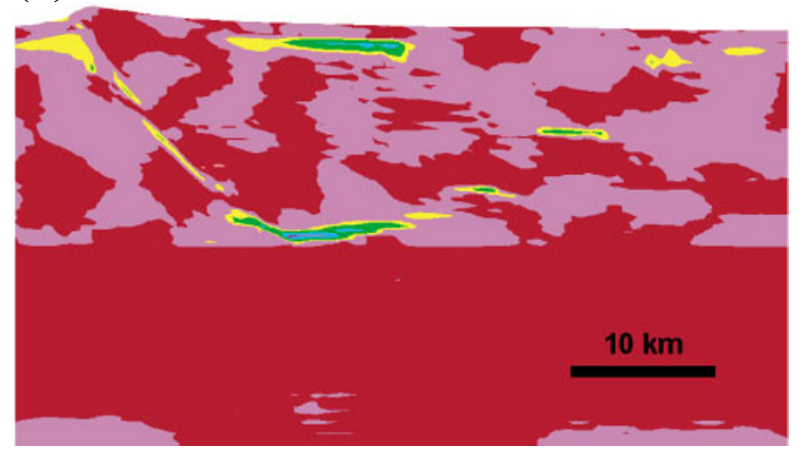

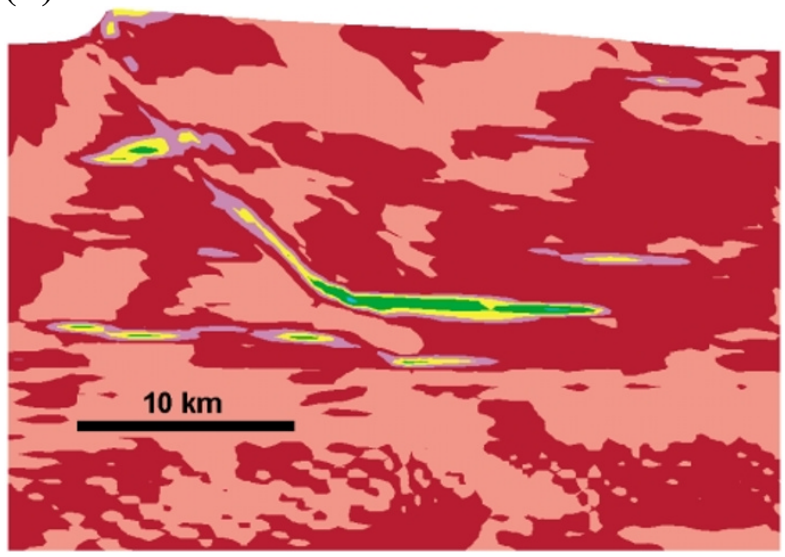

Fig. 5. Plots of instantaneous volumetric strain rate (a) Zoom into model with geothermal gradient $20^{\circ} \mathrm{C} \mathrm{km}^{-1}$. Dark Red: $1.6 \times 10^{-11} \mathrm{~s}^{-1}$ : Purple: $1.2 \times 10^{-11} \mathrm{~s}^{-1}$ : Yellow: $0.8 \times 10^{-11} \mathrm{~s}^{-1}$. Contour interval: $4 \times 10^{-12} \mathrm{~s}^{-1}$. Total shortening $1.3 \%$. (b) Zoom into model with geothermal gradient $20^{\circ} \mathrm{C} \mathrm{km}^{-1}$. Dark blue: $6 \times 10^{-11} \mathrm{~s}^{-1}$ : Light Green: $1.4 \times 10^{-11} \mathrm{~s}^{-1}$ : Yellow: $4 \times 10^{-12} \mathrm{~s}^{-1}$. Contour interval: $2 \times 10^{-12} \mathrm{~s}^{-1}$. Total shortening $2 \%$. (c) Zoom into model with geothermal gradient $40^{\circ} \mathrm{C} \mathrm{km}^{-1}$. Dark green: $3.2 \times 10^{-11} \mathrm{~s}^{-1}$ : Yellow: $2.4 \times 10^{-11} \mathrm{~s}^{-1}$ : Purple: $1.6 \times 10^{-11} \mathrm{~s}^{-1}$. Contour interval: $0.8 \times 10^{-11} \mathrm{~s}^{-1}$. Total shortening $1.5 \%$. (d) Zoom into model with geothermal gradient $40^{\circ} \mathrm{C} \mathrm{km}^{-1}$. Dark green: $2 \times 10^{-11} \mathrm{~s}^{-1}$ : Yellow: $1.2 \times 10^{-11} \mathrm{~s}^{-1}$ : Purple: $0.8 \times 10^{-11} \mathrm{~s}^{-1}$. Contour interval: $4 \times 10^{-12} \mathrm{~s}^{-1}$. Total shortening $2 \%$.

is totally controlled by the fluid pressure as indicated by Eq. (14). On the other hand, for the viscous part of the crust, $\sigma_{2}$ is still given by Eq. (5) and $\sigma_{1}$ can then be obtained from Eq. (6) and is independent of the straining history or of the fluid pressure. Clearly, $\left(\sigma_{1}-\sigma_{2}\right)$ in the viscous material can now be relatively large especially just below the plasticviscous transition and is independent of fluid pressure as indicated by Eqs. (2) and (6). This lack of dependence upon fluid pressure in a viscous material is an expression of the fact that the influence of fluid on the mechanical properties of viscous materials is of a chemical nature, and is expressed through effects upon $A$ and $Q$ in Eq. (6) (see Regenauer-Lieb and Yuen, 2003) whereas the influence of fluids upon the mechanical properties of plastic materials is, to first order, of a mechanical nature such that the grains are forced apart by the fluid thus influencing the effective normal stresses and bringing the stress state to, or closer to, the yield surface.

This situation is not changed substantially by introducing more complicated constitutive relations, such as elasticplastic-viscous behaviour, as one approaches the plasticviscous transition from above. A simple elastic-plasticviscous constitutive law is the Burger Solid consisting of an elastic-viscous element, in this case a Kelvin element in series with a Maxwell element (see Jaeger, 1962), in turn in series with a Mohr-Coulomb element. The viscosity used here in both the Maxwell and Kelvin elements are linear Newtonian with a weak temperature dependence. The mechanical parameters assumed here are given in Table 1. This kind of behaviour is what might be expected from pressure solution operating in conjunction with fracturing and other brittle processes in the mid to upper crust. Figure 7 shows the results of using such an elastic-plastic-viscous material. Shear zones are well developed in the upper crust as shown in Fig. 7(a) and strong horizontal dilational regions are again developed especially at the plastic-viscous transition (Fig. 7b). The influence of fluid pressure upon $\left(\sigma_{1}-\sigma_{2}\right)$ in the upper part of the crust is similar to using a Mohr Coulomb material as shown in Fig. 7(c) although the general value of $\left(\sigma_{1}-\sigma_{2}\right)$ is now larger than with a strict elastic-Mohr Coulomb material, particularly within shear zones.

With the above basic principles in mind, it is then possible to model the geometry of the Nagamachi-Rifu Fault. Dilatant zones, representing zones of increased porosity and hence fluid content, develop as approximately horizontal tabular regions mainly on the hanging wall of the fault and as en echelon arrays along a diffuse shear zone conjugate to 
(a)
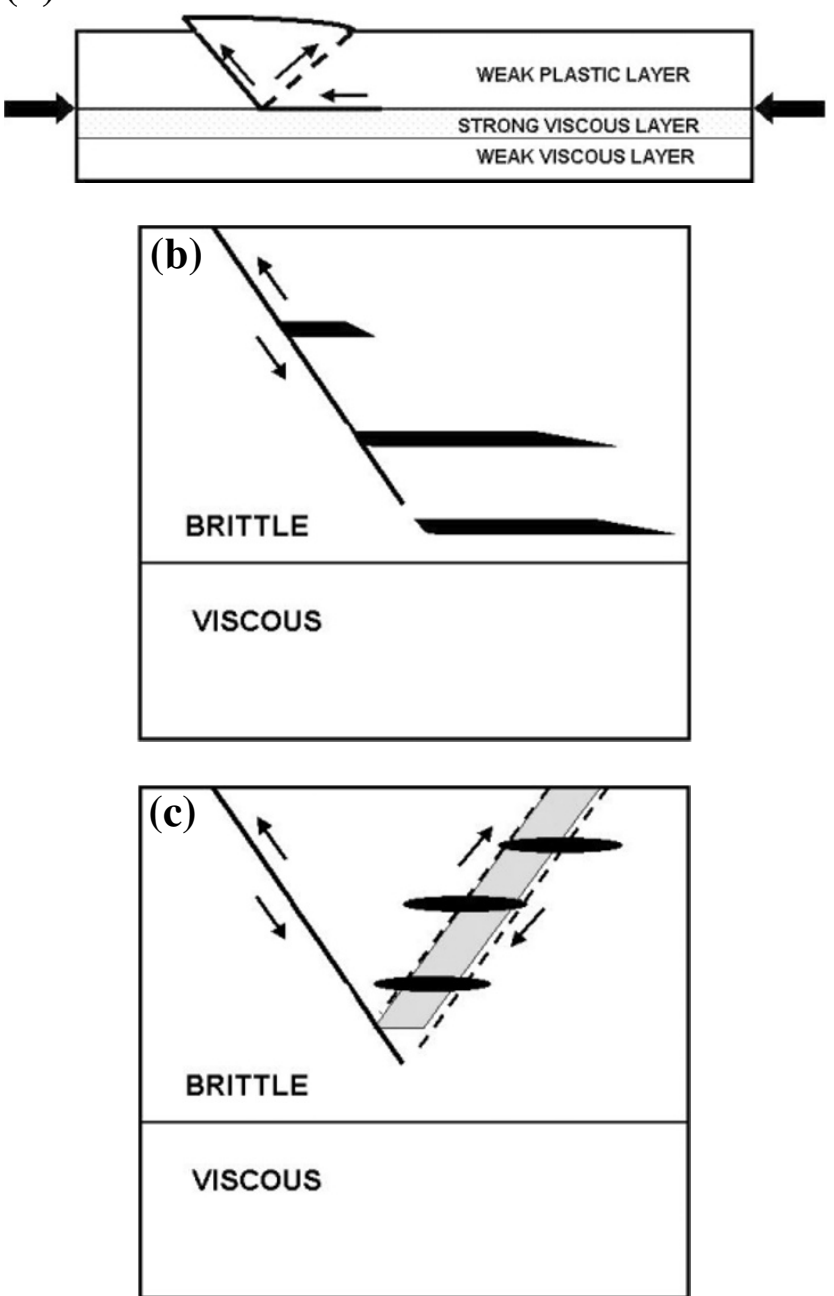

Fig. 6. Cartoons summarising the essence of the results. (a) Almost all of the strain in the model is partitioned to form a plastic wedge, bounded on the left by the initial weak fault and on the right by a diffuse shear zone. The development of this wedge is accommodated by sliding on the boundary between the weak plastic upper crust and the strong portion of the viscous lower crust. (b) Cartoon showing the development of tensional dilatant zones on the hangingwall of a thrust fault. (c) Cartoon showing the development of tensional en echelon dilatant zones within a broad shear zone on the hangingwall of a thrust fault.

the main fault. This pattern of dilatancy is the direct result of the formation of a plastic wedge and the shear accommodation at the base of the plastic upper crust as shown in Fig. 6(a). As the deformation continues the main region of dilatancy is concentrated into a horizontal tabular zone coincident with the listric continuation of the original fault. This mimics the observed seismic images of the Nagamachi-Rifu Fault system quite closely and suggests a general origin for seismic reflectors in other environments (see Drummond et al., 2004, this volume).

In particular, as indicated in Fig. 4(d), the dilatant regions that develop are regions of strong instantaneous fluid flow upwards across isotherms. Hence, following the arguments of Phillips (1991, p. 107) that the rate of mineral alteration is proportional to the scalar product of Darcy flow and the temperature gradient, one would expect mineral alteration haloes such as precipitation of quartz and alter- (a)

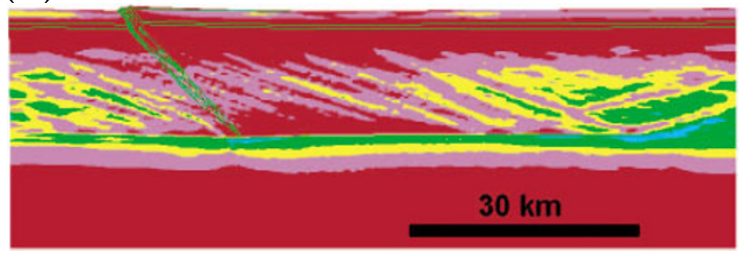

(b)

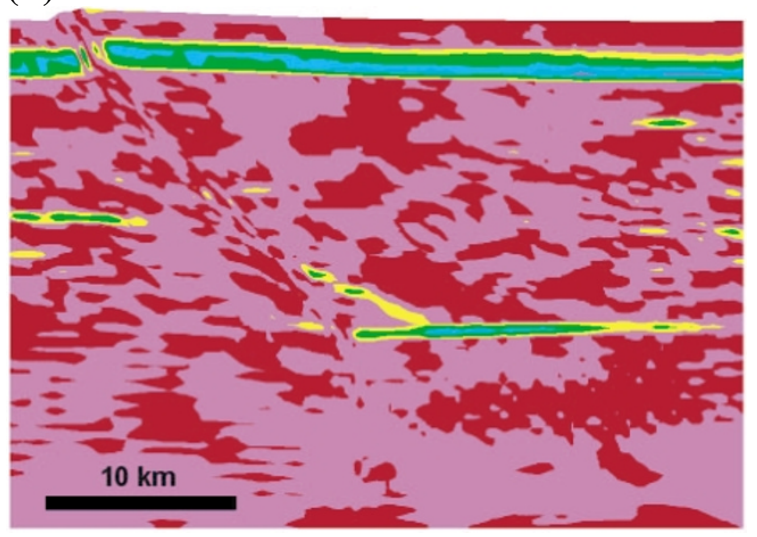

(c) $\quad\left(\sigma_{1}-\sigma_{2}\right) 10^{8} \mathrm{~Pa}$

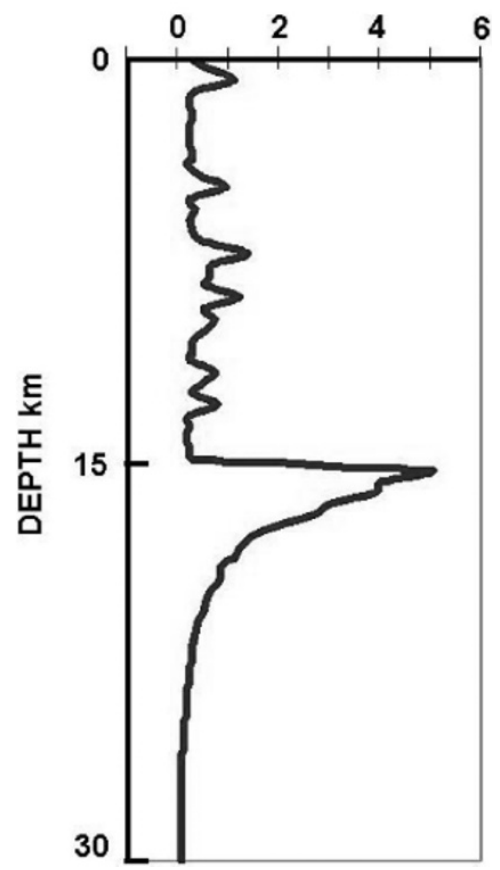

Fig. 7. Results using a Burger elastic-plastic-viscous model of the upper crust. Otherwise the situation is as illustrated in Fig. 2. (a) Spatial distribution of $\left(\sigma_{1}-\sigma_{2}\right)$; dark blue: $700 \mathrm{MPa}$, yellow: 200-300 MPa; dark red: less than $100 \mathrm{Mpa}$, contour interval: $100 \mathrm{MPa}$. Outline of fault and of seal layer in green. (b) Zoom into area around the initial fault showing distribution of instantaneous volumetric strain rate; Darkest blue: $1.5 \times 10^{-12} \mathrm{~s}^{-1}$, yellow: 2.5 to $5.0 \times 10^{-13} \mathrm{~s}^{-1}$; contour interval: $2.5 \times 10^{-13} \mathrm{~s}^{-1}$. (c) Vertical distribution of $\left(\sigma_{1}-\sigma_{2}\right)$; section is $40 \mathrm{~km}$ from left hand side of Fig. 7(a).

ation of feldspar to micas in association with these regions. Although the increase in fluid content associated with increased porosity is presumably what is imaged by seismic studies in modern terrains, it is perhaps this alteration that 
is identified in modern seismic images of ancient "bright spots" (see Drummond et al., 2004, this volume).

In addition to the above processes, regions of stagnant fluid flow develop in the viscous lower crust as discussed by Connolly and Podladchikov (2004). Here, reversals in the gradient of hydraulic head in the lower crust result in down flow and up flow regions with stagnant flow regions between. The development of these layers in the models presented here is not accompanied by inelastic porosity increases as in the plastic upper crust because no coupling between deformation and volumetric strain rate is included in the viscous constitutive laws. Mineral alteration will still be associated with these zones but the style of alteration will be asymmetric in the sense that it will be different on the upper and lower surfaces of the layers. This arises since the top of one of these layers is associated with fluid flow up a thermal gradient whereas the base of the layer is associated with fluid flow down a thermal gradient. Perhaps future seismic imaging can distinguish between the homogeneous alteration patterns to be expected with bright spots in the upper crust as opposed to asymmetric alteration to be expected with bright spots in the lower crust?

Acknowledgments. The authors thank the organisers of the Second Conference on Slip and Flow Processes in the Seismogenic Region for invitations to attend and also thank Professor Hirahara and an anonymous reviewer for greatly improving the paper with their insightful comments. Enormous insights into the mechanical behaviour of the crust were gained at the feet of a very special Sake Master.

\section{References}

Bear, J., Dynamics of Fluids in Porous Media, Elsevier, New York, 1972. Bercovici, D. and Y. Ricard, Energetics of a two-phase model of lithospheric damage, shear localisation and plate boundary formation, Geophysical Journal International, b, 2002.

Borja, I. R. and A. Aydin, Computational modelling of deformation bands in granular media. I. Geological and mathematical framework, Comput. Methods Appl. Mech. Engrg., 193, 2667-2698, 2004.

Connolly, J. A. D. and Y. Podladchikov, Temperature-dependent viscoelastic compaction and compartmentalisation in sedimentary basins, Tectonophysics, 324, 137-168, 2000.

Connolly, J. A. D. and Y. Podladchikov, Fluid flow in compressive settings: Implications for mid-crustal reflectors and downward fluid migration, $J$. Geophys. Res., 2004 (in press).

Cox, S. F., M. A. Etheridge, and V. J. Wall, Fluid pressure regimes and fluid dynamics during deformation of low-grade metamorphic terranes, implications for the genesis of mesothermal gold deposits, in Greenstone
Gold and Crustal Evolution, pp. 46-53, Geol Assoc. Canada, 1990.

Desai, C. S. and J. T. Christian, Numerical Methods in Geomechanics, McGraw-Hill, New York, 783 pp., 1977.

Drummond, B. J., B. E. Hobbs, and B. R. Goleby, The role of crustal fluids in the tectonic evolution of the Eastern Goldfields Province of the Archaean Yilgarn Craton, Western Australia, Earth Planets Space, 56, this issue, 1163-1169, 2004.

Hunt, J. M., Generation and migration of petroleum from abnormally pressured fluid compartments, AAPG Bulletin, 74, 1-12, 1990.

Iio, Y. and Y. A. Kobayashi, Physical understanding of the beginning of large intraplate earthquakes, Earth Planets Space, 54, 1001-1004, 2002.

ITASCA. FLAC, Fast Lagrangian Analysis of Continua, User's Guide, Version 4.00, ITASCA, Minnesota, USA, 2002.

Jaeger, J. C., Elasticity, Fracture and Flow, Methuen, London, 208 pp, 1962.

Nadai, A., Theory of Flow and Fracture of Solids, McGraw-Hill, New York, 572 pp, 1950.

Nicolas, A. and J. P. Poirier, Crystalline Plasticity and Solid State Flow in Metamorphic Rocks, Wiley, London, 1976.

Needleman, A., Computational modelling of material failure, Applied Mechanics Reviews, 47, 34-42, 1994.

Paterson, M. S., Experimental Rock Deformation. The Brittle Field, Springer-Verlag, 254 pp, 1978.

Petrini, K. and Y. Podladchikov, Lithospheric pressure-depth relationship in compressive regions of thickened crust, J. metamorphic Geol., 18, 76-77, 2000.

Phillips, O. M., Flow and Reactions in Permeable Rocks, Cambridge University Press, 285 pp., 1991.

Ranalli, G., Rheology of the Earth, Allen and Unwin, 366 pp., 1987.

Regenauer-Lieb, K., Dilatant plasticity applied to Alpine collision: Ductile void growth in the intraplate area beneath the Eifel volcanic field, Journal of Geodynamics, 27, 1-21, 1999.

Regenauer-Lieb, K. and D. A. Yuen, Modelling shear zones in geological and planetary sciences: Solid-fluid and fluid-thermal-mechanical approaches, Earth Science Reviews, 63, 295-349, 2003.

Scheidegger, A. E., The Physics of Flow through Porous Media, Univ. Toronto Press, Toronto, 1974.

Sibson, R. H., Frictional constraints on thrust, wrench and normal faults, Nature, 249, 542-4, 1974.

Stuwe, K. and M. Sandiford, Contribution of deviatoric stresses to metamorphic P-T paths: An example appropriate to low-P. high-T metamorphism, J. metamorphic Geol., 12, 445-454, 1994.

Tvergaard, V., Effect of yield surface curvature and void nucleation on plastic flow localisation, Journal of Mechanics and Physics of Solids, 35, 43-60, 1987.

Umino, N., H. Ujikawa, S. Hori, and A. Hasegawa, Distinct S-wave reflectors (bright spots) detected beneath Nagamachi-Rifu fault, NE Japan, Earth Planets Space, 54, 1021-1026, 2002.

Vermeer, P. A. and R. de Borst, Non-associated plasticity for soils, concrete and rock, HERON, 29, 1-64, 1984.

B. E. Hobbs (e-mail: Bruce.Hobbs@csiro.au), A. Ord, K. RegenauerLieb, and B. Drummond 